\title{
A CONVENÇÃO DE SINGAPURA: UMA GRANDE CONTRIBUIÇÃO PARA A MEDIAÇÃO INTERNACIONAL E O DIREITO PROCESSUAL CIVIL DOS PAÍSES SIGNATÁRIOS ${ }^{1}$
}

\section{SINGAPORE CONVENTION ON MEDIATION: A HUGE CONTRIBUTION TO THE \\ DEVELOPMENT OF THE INTERNATIONAL MEDIATION AND SIGNATORIES COUNTRIES' CIVIL PROCEDURAL LAW}

Alberto Elisavetsky

Diretor do Programa de Pós-Graduação em Resolução de Conflitos e Novas Tecnologias da UNTREF. Diretor do Observatório de Conflitos da UNTREF. Coordenador da Seção Espanhola do Centro Nacional de Novas Tecnologias Aplicadas à Resolução de Disputas da Universidade de Massachusetts Amherst (Cyberweek). Professor Visitante do Mestrado em Mediação Familiar do Ilustre Colégio de Advogados de Valência, Espanha, disciplina Novas Tecnologias e Resolução de Conflitos. Professor do Mestrado em Resolução de Conflitos da Universidade Nacional de Lomas de Zamora, disciplina: Novas Tecnologias e Resolução de Conflitos. Professor Aprovado pela Federação Argentina de Conselhos Profissionais em Ciências Econômicas (FACEP). Professor Titular Presencial e Modalidades Virtuais da Universidade Nacional de Três de Febrero (UNTREF), Instituto Superior La Suisse - CEPEC Instituto Universitário da Polícia Federal, Universidade de Belgrano, Universidade de Concepción del Uruguai. Diretor Geral de Eventos Virtuais, serviços de educação a distância interativa.

\footnotetext{
${ }^{1}$ Artigo recebido em 18/11/2021, sob dispensa de revisão.
} 
Revista Eletrônica de Direito Processual - REDP.

Rio de Janeiro. Ano 16. Volume 23. Número 1. Janeiro a Abril de 2022

Periódico Quadrimestral da Pós-Graduação Stricto Sensu em Direito Processual da UERJ

Patrono: José Carlos Barbosa Moreira (in mem.). ISSN 1982-7636. pp. 01-12

www.redp.uerj.br

Criador e Diretor Tecnológico do Simediar (projeto de simulação de mediação remota). Diretor da ODR LATINOAMERICA (Rede social especializada declarada Embaixada da Paz pela Fundación Mil Milenios de Paz, Peace Foundation, UNESCO). Embaixador da Paz para a Fundação dos Mil Milênios da Paz, Fundação da Paz, UNESCO. Argentina. E-mail: elisavetsky@gmail.com

Maria Victoria Marun Advogada e mediadora. Professora Sênior de Ciências Jurídicas. Especialista em Ensino Universitário. Diretora do Centro de Resolução de Conflitos da Ordem dos Advogados do $3^{\circ}$ Circ. Judicial de Mendoza. Argentina. Professora Universitária. Pósgraduado em Direito Privado. Formadora em Resolução de Conflitos em Instituições de Ensino. Professora do Curso de PósGraduação em Resolução de Conflitos e Novas Tecnologias UNTREF. Membro fundadora da Academia de ODR Latino America Membro do Fórum Internacional de Mediadores Profissionais. Colaboradora acadêmica e palestrante em diversos eventos científicos nacionais e internacionais. Autora de várias produções acadêmicas e publicações sobre assuntos de resolução de conflitos. Argentina.

RESUMO: O presente artigo pretende abordar como a Convenção de Singapura, até agora o instrumento internacional mais importante sobre mediação, promoveu a chamada mediação internacional. Com isso, forneceu-se às partes envolvidas em um litígio uma estrutura eficiente e uniforme para acordos internacionais obtidos via mediação, estabelecendo-se, por conseguinte, um quadro jurídico harmonizado apto a oferecer segurança para o direito de invocar acordos de solução e execução. Tal cenário, sem dúvidas, contribui para o Direito 
Revista Eletrônica de Direito Processual - REDP.

Rio de Janeiro. Ano 16. Volume 23. Número 1. Janeiro a Abril de 2022

Periódico Quadrimestral da Pós-Graduação Stricto Sensu em Direito Processual da UERJ

Patrono: José Carlos Barbosa Moreira (in mem.). ISSN 1982-7636. pp. 01-12

www.redp.uerj.br

Processual Civil dos Estados Signatários. O objetivo desse artigo, dentre outros, consiste em analisar diversos aspectos atinentes ao conteúdo regulatório da Convenção de Singapura.

PALAVRAS-CHAVE: Convenção de Singapura; mediação internacional; execução transfronteiriça; mediação comercial.

ABSTRACT: This article aims to analyze how the Singapore Convention on Mediation, the most important instrument that deals with mediation issues, has promoted international mediation. Such Convention has been providing to the litigating parties an efficient and uniform structure related to International agreements obtained through mediation, establishing a legal framework able to offer security for the right to invoke a settlement and enforcement agreements. This scenario contributes to the Civil Procedural Law of the signatories countries. The main objective of the paper is to deal with different aspects regarding the Singapore Convention's regulatory content.

KEYWORDS: Singapore Convention on Mediation; international mediation; cross-border enforcement, commercial mediation.

\section{INTRODUÇÃO}

A Convenção de Singapura surgiu como solução para a preocupação que se tinha gerado no Grupo de Trabalho da UNCITRAL (Comissão das Nações Unidas para o Direito do Comércio Internacional), sobre a dificuldade que surgia na execução transfronteiriça dos acordos decorrentes da mediação.

Muitas vezes, na prática, os acordos transacionais relacionados ao comércio internacional, firmados em decorrência de mediações transfronteiriças, apresentavam um panorama muito difícil para sua execução, nos casos de descumprimento.

Até a entrada em vigor da Convenção de Singapura, a mediação não contava com um regulamento que facilitasse o reconhecimento e a execução dos seus acordos transacionais 
Revista Eletrônica de Direito Processual - REDP.

Rio de Janeiro. Ano 16. Volume 23. Número 1. Janeiro a Abril de 2022

Periódico Quadrimestral da Pós-Graduação Stricto Sensu em Direito Processual da UERJ

Patrono: José Carlos Barbosa Moreira (in mem.). ISSN 1982-7636. pp. 01-12

www.redp.uerj.br

internacionais, o que obrigava as partes, em caso de descumprimento, a utilizar a eventual cláusula de resolução de litígios acordada no respectivo contrato para obter a sua execução.

Ou seja, após se submeter à mediação, a parte lesada pelo descumprimento do acordo teve que recorrer à arbitragem ou jurisdição ordinária para fazer cumprir o acordo firmado, o que além de implicar em custos adicionais, desvalorizou o uso da mediação como forma de resolução de conflitos internacionais.

A Convenção não regula nenhum procedimento para a efetivação dos acordos. Referese simplesmente à legislação do Estado de destino onde o acordo deve ser executado.

Assim, a Convenção de Singapura veio promover a Mediação Internacional como um valioso instrumento para a celebração de acordos com possibilidade de execução e, também, proporcionando normas a serem aplicadas nos processos judiciais dos países signatários.

\section{HISTÓRIA}

A chamada "Convenção de Cingapura sobre Mediação" foi elaborada no Grupo de Trabalho II, da Comissão das Nações Unidas para o Direito Comercial Internacional (UNCITRAL, na sigla em inglês) e foi aprovada pela Assembleia Geral das Nações Unidas em 20 de dezembro, 2018.

Desde a sua criação em 1996, a UNCITRAL tem desenvolvido um trabalho de harmonização e unificação progressiva do Direito Comercial Internacional, através da criação de instrumentos legislativos como Convenções Internacionais, Leis Modelo e Regulamentos; encorajando sua adoção pelo maior número possível de Estados.

No que diz respeito à mediação comercial internacional, a UNCITRAL desenvolveu e promoveu a adoção de diversos instrumentos, que são os seguintes:

- As Regras de Conciliação de 1980;

- A Lei Modelo de Conciliação Internacional de Negócios de 2002;

- Grupo de Trabalho II - Arbitragem e conciliação / solução de controvérsias; 
- Grupo de Trabalho III - A Assembleia, na sua Sessão da Quadragésima Terceira, realizada em 2010, atribuído a este Grupo de Trabalho ou regulamento na área da resolução de litígios on-line;

- Entre 2010 e 2016, o Grupo III da UNCITRAL elaborou recomendações para o desenvolvimento das atividades de ODR em cada uma das suas sessões anuais;

- Na 49a sessão do ano de 2016, a UNCITRAL emitiu Notas Técnicas como resultado do trabalho realizado ao longo de um período de seis anos, com o objetivo de fornecer uma estrutura regulatória de Soft Law às atividades de ODR;

- A Lei Modelo de 2018 sobre Mediação Comercial Internacional e Acordos de Liquidação Internacional Resultantes da Mediação (que altera a Lei Modelo de 2002);

- A Convenção das Nações Unidas sobre Acordos de Liquidação Internacionais Resultantes da Mediação de 2018 (Convenção de Cingapura), baseada na Convenção de Nova York-1958, sobre reconhecimento e execução de sentenças proferidas por arbitragem, em suas diretrizes: Autonomia da vontade; Flexibilidade de procedimentos; Menor incidência de diretivas estaduais; e soft law.

A Convenção de Singapura foi aberta para assinatura em 7 de agosto de 2019 em Singapura, sendo assinada nesse ato por 46 Estados. No que se refere aos países da América Latina, a Convenção foi assinada pela Colômbia, Chile, Equador, Honduras, Jamaica, Paraguai, Uruguai e Venezuela, e recentemente a República do Brasil ratificou o Tratado, entre outros países.

\section{IMPORTÂNCIA DA CONVENÇÃO DE SINGAPURA}

Como a Convenção de Nova York de junho de 1958 sobre o reconhecimento e a execução de sentenças arbitrais estrangeiras, a Convenção de Singapura fornece às partes uma estrutura uniforme e eficiente para a execução de acordos internacionais de solução resultantes da mediação. 
Seu objetivo é resolver o problema executivo desses acordos, que fornece força vinculativa e permite que sejam reconhecidos e executados através de um procedimento relativamente simples.

A Convenção estabelece um quadro jurídico harmonizado para o direito de invocar acordos de solução, bem como para a sua execução. A Convenção é um instrumento para facilitar o comércio internacional e promover a mediação como um método alternativo e eficaz de solucionar disputas comerciais. Como instrumento internacional vinculativo, espera-se oferecer segurança e estabilidade ao quadro de mediação internacional, o que contribuirá para a consecução dos Objetivos de Desenvolvimento Sustentável.

A Convenção de Cingapura é talvez o instrumento internacional mais importante até hoje em matéria de mediação, que além de seu artigo $2^{\circ}$ estabelece as regras processuais aplicáveis à execução de acordos de liquidação, determinando que a execução do acordo de liquidação seja ordenada de acordo com o cumprimento das normas processuais do Estado em que o acordo se destina a ser executado. E é por isso que no título deste trabalho expressamos que significa como Ordem normativa uma grande contribuição ao Direito Processual Civil dos Estados signatários.

\section{CONTEÚDO REGULATÓRIO}

\subsection{Matérias às quais se aplica}

Princípio Geral: é aplicável a qualquer acordo resultante de mediação que tenha sido celebrado por escrito pelas partes para resolver uma disputa comercial ("contrato de transação") e que, no momento da conclusão, seja internacional.

Exceções: operações nas quais um consumidor participa para fins pessoais, familiares ou domésticos; direito de família, direito de herança ou direito do trabalho; acordos de solução que possam ser executados como sentença ou sentença arbitral.

\subsection{Estados em que a Convenção se aplicará}


Como já dissemos em pontos anteriores, a Convenção de Cingapura foi aberta para assinatura em 7 de agosto de 2019 em Cingapura e, tendo as características de um Tratado Internacional, foi assinada nesse ato por 46 Estados. Portanto, desde aquela data, houve Estados que ratificaram, aprovaram ou aceitaram esta Convenção, sendo o Brasil um deles. A assinatura inicial não é suficiente. Uma vez ratificado por um Estado, ele o aplicará a todos os acordos de transação internacionais resultantes de mediação comercial. Será irrelevante que o lugar onde o acordo foi celebrado, a nacionalidade e estabelecimento das partes e do mediador, etc., correspondam a Estados que não são signatários da Convenção. Portanto, não há obrigação de reciprocidade. É irrelevante se o acordo está em um documento público ou não. Assim, é irrelevante se foi formalizado pela autoridade de um Estado parte ou não.

A qualquer momento, os Estados podem fazer reservas. O primeiro é não aplicar a Convenção a acordos de liquidação dos quais o Estado ou uma de suas agências seja parte. A segunda, a reserva de aplicação da Convenção apenas aos casos em que as partes no acordo de solução assim o manifestem.

\subsection{Quando começa a validade do seu aplicativo}

A partir do término do prazo de seis meses contados da homologação. A Convenção se aplica apenas a acordos de liquidação assinados após sua entrada em vigor.

\subsection{Relacionamento com outros instrumentos}

A Convenção não exclui a aplicação de outras normas se forem mais favoráveis para sua aplicação. Ou seja, se o Contrato não permitir a execução do contrato por não cumprimento de suas regras, as partes poderão invocar outro instrumento que permita a execução.

\subsection{Definições}


Revista Eletrônica de Direito Processual - REDP.

Rio de Janeiro. Ano 16. Volume 23. Número 1. Janeiro a Abril de 2022

Periódico Quadrimestral da Pós-Graduação Stricto Sensu em Direito Processual da UERJ

Patrono: José Carlos Barbosa Moreira (in mem.). ISSN 1982-7636. pp. 01-12

www.redp.uerj.br

No artigo $2^{\circ}$, a Convenção define termos e conceitos:

Quando a parte tiver: Mais de um estabelecimento: prevalecerá o que tiver a relação mais próxima com a controvérsia; não haverá estabelecimentos: prevalecerá seu local habitual de residência.

É considerado um Contrato "escrito" se houver alguma evidência de seu conteúdo. Teste: comunicação eletrônica que permite acesso a informações para consultas subsequentes.

"Mediação" é qualquer procedimento pelo qual as partes tentam chegar a uma solução amigável de sua disputa com a assistência de um ou mais terceiros (“o mediador”) que não têm autoridade para impor a eles uma solução.

\subsection{Questões processuais}

I. Cada Parte da Convenção ordenará a execução de acordos de transação, de acordo com suas normas processuais e nas condições estabelecidas nesta Convenção;

II. Se surgir uma controvérsia sobre uma questão que uma parte alega que foi resolvida por um acordo de transação, a outra parte permitirá que a mesma seja invocada de acordo com suas regras processuais e nas condições estabelecidas nesta Convenção, para demonstrar que o problema já foi resolvido;

III. As formalidades são: a) O contrato de transação assinado pelas partes; b) Prova de que o contrato de transação foi alcançado como resultado da mediação, 1) Assinatura do mediador no acordo; 2) Documento assinado pelo mediador indicando que a mediação foi realizada; 3) Certificado emitido pelo administrador do ODR; 4) Qualquer outra prova que a autoridade competente considere aceitável; 5) Assinatura e comunicação eletrônica : a) se surgirem identidades das partes ou do mediador e sua intenção com relação às informações contidas na comunicação eletrônica; b) Se o método utilizado é confiável ou considerado apropriado para os fins para os quais a comunicação eletrônica foi gerada ou transmitida, levando em consideração todas as circunstâncias do caso, incluindo qualquer acordo pertinente; ou foi demonstrado na prática que, por si só ou com o apoio de outras evidências, o referido método cumpriu as funções estabelecidas na seção a); 6) Se o acordo não for redigido em um 
Revista Eletrônica de Direito Processual - REDP.

Rio de Janeiro. Ano 16. Volume 23. Número 1. Janeiro a Abril de 2022

Periódico Quadrimestral da Pós-Graduação Stricto Sensu em Direito Processual da UERJ

Patrono: José Carlos Barbosa Moreira (in mem.). ISSN 1982-7636. pp. 01-12

www.redp.uerj.br

idioma oficial da Parte na Convenção, em que medidas são solicitadas, a autoridade competente poderá solicitar uma tradução do acordo para esse idioma; 7) A autoridade competente pode exigir qualquer documento necessário para verificar se os requisitos estabelecidos na Convenção foram cumpridos; 8) Ao examinar o pedido de medidas, a autoridade competente deve agir rapidamente;

$I V$. A execução pode ser negada a pedido da parte contra a qual é solicitada, se fornecer evidências de que: a) Uma das partes no acordo tinha algum tipo de deficiência; b) O contrato: é nulo, ineficaz ou não pode ser cumprido de acordo com a lei; não é vinculativo, ou não é definitivo, conforme estipulado no próprio contrato; ou foi posteriormente modificado; c) As obrigações estipuladas no contrato de transação: foram cumpridas; ou eles não são claros ou compreensíveis; d) A concessão de medidas seria contrária aos termos do contrato de transação; e) O mediador cometeu uma violação grave das regras aplicáveis ao mediador ou mediação, sem as quais essa parte não teria celebrado o contrato de solução; f) O mediador não revelou às partes circunstâncias que teriam levantado dúvidas fundamentadas sobre a imparcialidade ou independência do mediador, ou exercido uma influência indevida sobre uma das partes, que não teria entrado em acordo se o mediador as tivesse divulgado;

$V$. A autoridade competente da Parte na Convenção que solicitar medidas nos termos do artigo 4 também poderá recusar sua concessão se considerar que: a) A concessão das medidas solicitadas seria contrária à ordem pública dessa Parte; b) $\mathrm{O}$ objeto da controvérsia não é suscetível de ser resolvido por mediação, de acordo com a lei dessa Parte;

VI. Solicitações ou reivindicações paralelas: Se uma solicitação ou reclamação referente a um acordo de transação que possa afetar as medidas solicitadas nos termos do artigo 4, a autoridade competente da parte na Convenção em que essas medidas sejam solicitadas, poderá, se julgar conveniente, adiar a decisão e, a pedido de uma das partes, ordenar que a outra conceda garantias adequadas;

VII. Outras leis ou tratados: Se uma solicitação ou reclamação referente a um acordo de transação que possa afetar as medidas solicitadas nos termos do artigo 4 foi submetida a um órgão judicial, um tribunal arbitral ou qualquer outra autoridade competente, a autoridade competente da Parte na Convenção em que essas medidas sejam solicitadas, poderá, se julgar 
Revista Eletrônica de Direito Processual - REDP.

Rio de Janeiro. Ano 16. Volume 23. Número 1. Janeiro a Abril de 2022

Periódico Quadrimestral da Pós-Graduação Stricto Sensu em Direito Processual da UERJ

Patrono: José Carlos Barbosa Moreira (in mem.). ISSN 1982-7636. pp. 01-12

www.redp.uerj.br

apropriado, adiar a decisão e, a pedido de uma das partes, ordenar à outra que conceda garantias adequadas;

\subsection{Questões de direito internacional}

I. Reservas: 1) Qualquer parte da convenção pode declarar que: a) A presente Convenção não se aplica aos acordos de transação dos quais é parte; b) Aplicara a presente Convenção somente na medida em que as partes no acordo tenham concordado com sua aplicação. Não podem ser feitas mais reservas do que aquelas expressamente autorizadas por este artigo; 2) As Partes da Convenção podem fazer reservas em qualquer momento. As reservas feitas no momento da assinatura devem ser confirmadas no momento da ratificação, aceitação ou aprovação. As referidas reservas entrarão em vigor simultaneamente com a entrada em vigor desta Convenção com relação à Parte na Convenção que as formulou. As reservas feitas no momento da ratificação, aceitação ou aprovação ou adesão à presente Convenção, ou no momento em que uma declaração foi feita de acordo com o artigo 13, entrarão em vigor simultaneamente com a entrada em vigor da presente Convenção em relação à Parte na Convenção que as formulou. As reservas depositadas após a entrada em vigor da Convenção em relação a essa Parte entrarão em vigor seis meses após a data do depósito; 3) As reservas e suas confirmações serão deixadas com o depositário; 4) Qualquer Parte da Convenção que faça uma reserva de acordo com as disposições desta Convenção poderá retirá-la em qualquer momento. As retiradas de reservas serão depositadas junto ao depositário e entrarão em vigor seis meses após o depósito ter sido feito;

II. Efeitos nos contratos de transação: A presente Convenção e qualquer reserva ou retirada de uma reserva só se aplicarão a acordos de transação concluídos após a data em que a Convenção, reserva ou retirada da reserva entrar em vigor para a Parte na Convenção;

III. Depositário: O Secretário-Geral das Nações Unidas é designado como depositário da presente Convenção;

IV. Assinatura, ratificação, aceitação, aprovação, adesão: como todos os tratados internacionais, esta Convenção foi aberta à assinatura de todos os Estados em Singapura em 7 
Revista Eletrônica de Direito Processual - REDP.

Rio de Janeiro. Ano 16. Volume 23. Número 1. Janeiro a Abril de 2022

Periódico Quadrimestral da Pós-Graduação Stricto Sensu em Direito Processual da UERJ

Patrono: José Carlos Barbosa Moreira (in mem.). ISSN 1982-7636. pp. 01-12

www.redp.uerj.br

de agosto de 2019, e a partir dessa data, na sede das Nações Unidas em Nova York. A presente Convenção sendo sujeita a ratificação, aceitação ou aprovação pelos signatários. Esta Convenção está aberta à adesão de todos os Estados que não são signatários a partir da data em que estiver aberta para assinatura. Os instrumentos de ratificação, aceitação, aprovação ou adesão devem ser depositados junto ao depositário;

V. Participação de organizações regionais de integração econômica: Requisitos: a) Organização constituída por Estados soberanos com jurisdição sobre alguns assuntos regidos pela Convenção; b) Deverá apresentar ao depositário uma declaração sobre a competência transferida pelos Estados Membros; c) Notificar prontamente o depositário de qualquer alteração na distribuição de poderes; d) A Convenção não prevalecerá: 1) se, de acordo com o artigo 4, forem solicitadas medidas em um Estado que seja membro dessa organização e todos os Estados pertinentes de acordo com o disposto no parágrafo 1 do artigo 1. são membros dessa organização; 2) sobre o reconhecimento ou execução de sentenças entre os Estados membros dessa organização;

VI. Sistemas jurídicos não unificados: 1) Qualquer Parte que consista em duas ou mais unidades territoriais em que seja aplicado um regime jurídico diferente deve declarar (caso contrário, será aplicado em todas as unidades territoriais) quais são as unidades territoriais em que a convenção se aplica e pode a qualquer momento modificar sua declaração original substituindo-a por outra; 2) Notificação expressa ao Depositário; 3) Interpretações: a) Qualquer referência à lei de um Estado será interpretada como a lei ou regras processuais em vigor na unidade territorial relevante; b) Qualquer referência ao estabelecimento localizado em um Estado deve ser interpretada como o estabelecimento localizado na unidade territorial relevante; c) Qualquer referência à autoridade competente do Estado será interpretada como a autoridade competente da unidade territorial relevante;

VII. Procedimento de modificação: As partes podem propor uma emenda à Convenção: 1) Deve submetê-la ao Secretário-Geral das Nações Unidas. 2) O Secretário-Geral comunicará a modificação proposta às outras Partes, solicitando que indiquem se são a favor da convocação de uma conferência para examinar a proposta e colocá-la em votação. 3) Um terço das partes deve responder dentro de quatro meses para realizar a conferência; 4) A conferência das Partes 
Revista Eletrônica de Direito Processual - REDP.

Rio de Janeiro. Ano 16. Volume 23. Número 1. Janeiro a Abril de 2022

Periódico Quadrimestral da Pós-Graduação Stricto Sensu em Direito Processual da UERJ

Patrono: José Carlos Barbosa Moreira (in mem.). ISSN 1982-7636. pp. 01-12 www.redp.uerj.br

deve chegar a um consenso sobre cada modificação. Se não foi alcançado consenso, será necessária uma maioria de dois terços dos votos das Partes da Convenção presentes e votantes na conferência para aprovar a modificação; 5) O depositário enviará as modificações adotadas às Partes para ratificação, aceitação ou aprovação; 6) As modificações adotadas entrarão em vigor seis meses após a data do depósito do terceiro instrumento de ratificação, aceitação ou aprovação. 7) Quando uma modificação entrar em vigor, será vinculativa para as Partes que consentiram;

VIII. Reclamação: Qualquer parte pode denunciar a presente convenção mediante notificação formal por escrito dirigida ao depositário. A denúncia pode ser limitada a algumas unidades territoriais de um sistema jurídico não unificado ao qual a Convenção é aplicável. A denúncia entrará em vigor 12 meses após a data de recebimento da notificação pelo depositário. A Convenção continuará a ser aplicada aos acordos de solução firmados antes da denúncia entrar em vigor.

\section{REFERÊNCIAS:}

CONVENÇÃO DE SINGAPURA. Disponível em: https://uncitral.un.org/sites/uncitral.un.org/files/mediadocuments/uncitral/es/mediation _convention_s.pdf. 